\title{
Numerical and Experimental Investigation of Combustion and Knock in a Dual Fuel Gas/Diesel Compression Ignition Engine
}

\author{
A. Gharehghani, ${ }^{1}$ S. M. Mirsalim, ${ }^{1}$ and S. A. Jazayeri ${ }^{2}$ \\ ${ }^{1}$ Department of Mechanical Engineering, Amirkabir University of Technology, 424 Hafez Avenue, \\ P.O. Box 15875-4413, Tehran, Iran \\ ${ }^{2}$ Department of Mechanical Engineering, K. N. Toosi University of Technology, Molla-Sadra, Pardis, \\ P.O. Box 19395-1999, Tehran, Iran \\ Correspondence should be addressed to S. A. Jazayeri, jazayeri@kntu.ac.ir
}

Received 6 July 2011; Revised 10 September 2011; Accepted 15 October 2011

Academic Editor: Evangelos G. Giakoumis

Copyright ( 2012 A. Gharehghani et al. This is an open access article distributed under the Creative Commons Attribution License, which permits unrestricted use, distribution, and reproduction in any medium, provided the original work is properly cited.

Conventional compression ignition engines can easily be converted to a dual fuel mode of operation using natural gas as main fuel and diesel oil injection as pilot to initiate the combustion. At the same time, it is possible to increase the output power by increasing the diesel oil percentage. A detailed performance and combustion characteristic analysis of a heavy duty diesel engine has been studied in dual fuel mode of operation where natural gas is used as the main fuel and diesel oil as pilot. The influence of intake pressure and temperature on knock occurrence and the effects of initial swirl ratio on heat release rate, temperature-pressure and emission levels have been investigated in this study. It is shown that an increase in the initial swirl ratio lengthens the delay period for auto-ignition and extends the combustion period while it reduces $\mathrm{NO}_{x}$. There is an optimum value of the initial swirl ratio for a certain mixture intake temperature and pressure conditions that can achieve high thermal efficiency and low $\mathrm{NO}_{x}$ emissions while decreases the tendency to knock. Simultaneous increase of intake pressure and initial swirl ratio could be the solution to power loss and knock in dual fuel engine.

\section{Introduction}

Natural gas, because of cleaner nature of its combustion and also lower price compared with conventional liquid fuels, is the most attractive and widely accepted among alternative gaseous fuels. Diesel engines could easily be designed or modified to use natural gas in power production. Due to relative high compression ratio, high thermal efficiency is achievable from these engines. The objective is to increase the percentage of natural gas used as fuel by improving the engine design and combustion process with least exhaust emissions, together with thermal efficiencies compatible with the base engine [1]. There are some problems associated with the diesel engines conversion to dual fuel mode of operation. One of the problems is the knock occurrence at high load operation that the maximum power output of a dual fuel engine is limited by knock and another is the power loss due to lower power density of gaseous fuels. A great deal of numerical research into knock phenomena and power loss in dual fuel engines has been carried out. The combustion models, which are used for investigation, could be divided into two groups: multizone models and multi-dimensional models. Many combustion simulations of dual fuel engines have used multi-zone model to analyze the combustion. Karim simulated autoignition and knock in dual fuel engine using a two-zone model and detailed chemical kinetics including 14 species and 32 reactions [2]. Liu and Karim used a multizone model with 32 species and 138 reactions for prediction of ignition delay in a dual fuel engine [3]. Pirouzpanah and Kashani predicted the major pollutants in a direct injection dual fuel engine using a multi-zone model for pilot and two-zone model for gaseous fuel [4]. Abd-Alla et al. investigated the effects of EGR by using a quasi-twozone model with chemical kinetics including 41 species and 178 reactions [5]. Papagiannakis and Hountalas studied the effects of pilot fuel quantity on combustion characteristics 
in a dual fuel engine with a two-zone combustion model $[6,7]$. Recent developments on computer simulation ability enable us to use detailed multidimensional models to analyze the dual fuel engine combustion. Early CFD studies have used global reaction models to predict the combustion process [8-10]. More recently, detailed and reduced chemical kinetics reaction mechanisms have been introduced in CFD programs to give accurate prediction of combustion in an engine running on dual fuel mode of operation. Li and Williams used a reduced mechanism to predict knock limitation in a dual fuel engine [11]. Further numerical study of dual fuel engine combustion and emission was done by Kusaka et al. [12] and computational CFD modeling of dual fuel (gas/diesel) was carried out by Zhang et al., [13]. The most recent work on dual fuel engine simulation was done by Liu with reduced detailed kinetics mechanism for diesel fuel and a detailed kinetics mechanism for gaseous fuel [14]. In the present work, a new combustion model which is called partially stirred combustion model $[15,16]$ is added to KIVA-3V2 to simulate turbulence effects and fuels interactions in a dual fuel engine. Also, a reduced detailed chemical kinetics mechanism with 79 species and 292 reactions is considered to predict oxidation of fuels and knock in the dual fuel mode of operation.

\section{Model Description}

2.1. Combustion Model. The developed CFD code is a version of KIVA-3V [17] with relevant modifications in subroutines including chemical and physical models. The multidimensional KIVA-3V code is capable to calculate features of the transient, three-dimensional, multicomponent, chemically reactive and turbulent fluid flow processes. The combustion model of original KIVA-3V code is named perfectly stirred reactor model with detailed chemical kinetics [15]. Appropriate modifications of combustion chemistry exerted in KIVA-3V2 are presented here. New combustion model for partially stirred reactor model [16] which has been exerted in KIVA3V is as follows:

$$
\begin{aligned}
\frac{\Delta c_{m}}{\Delta t} & =\frac{c_{m-}^{k} c_{m}^{0}}{\tau}=\dot{\omega}_{r}\left(c_{m}^{k}\right) \frac{\tau_{\text {chem }}}{\tau_{\text {chem }}+\tau_{\text {mix }}} \\
& =\frac{c_{s}^{0}[\dot{\omega}]_{s r}^{0}}{c_{s}^{0}+R_{D}^{0} \tau-[\dot{\omega}]_{s r}^{0} \tau_{\text {mix }}},
\end{aligned}
$$

where $c_{m}^{0}$ and $c_{m}^{k}$ are the mean molar concentrations of species $m$ at the beginning and end of each reaction computational step; $\tau$ is the residence time scale or Lagrangian integration time step as used in KIVA3V; $\dot{\omega}_{r}\left(c_{m}^{k}\right)$ is the reaction rate of species $m$ in terms of PSR and $c_{s}^{0}$ is initial concentrations of reference species.

$[\dot{\omega}]_{s r}^{0}$ is the reaction rate of reference species $s$ at the beginning of each reaction computational step. The reference species is the one which has greatest risk of being driven negative.

The chemical kinetics timescale $\left(\tau_{\text {chem }}\right)$ is defined as time, needed for any species to reach its effective equilibrium state in a perfectly homogeneous condition. For one step "fast" combustion process, the chemical time scale can be defined as the consumption time of fuel or oxidant. In a complex chemistry, the definition of chemical time scale for each reversible elementary reaction relies on reference species in a reaction which can be expressed as

$$
\tau_{\text {chem }}^{-1}=-\frac{[\dot{\omega}]_{s r}^{0}}{\left(c_{s}^{0}+R_{D}^{0} \tau\right)},
$$

where $R_{D}^{0}$ is destruction or negative term. The turbulence time scale is defined as the time for eddy breakup in order to have mixture of fuel, oxidizer, and combustion products supposing that homogeneity exists in the mixture, which can be symbolized as

$$
\tau_{\text {mix }}=\frac{c k}{\varepsilon},
$$

where $k$ is turbulence kinetic energy, and $\varepsilon$ is $k$ 's dissipation rate, and $c$ is a constant assumed to be around 0.01 for diesel engine combustion [16].

When $\tau_{\text {mix }} \rightarrow 0$, the model described reduces to a perfectly stirred reactor approach. If the term $\dot{\omega}_{s r}^{0} \tau_{\text {mix }}$ dominates, the expression reproduces eddy break-up rate, $-c_{s}^{0} / \tau_{\text {mix }}$. In order to make sure that the initiation of combustion relies on exclusively chemistry, and the turbulence starts to have influence only after reactive events have already been taking place, the delay coefficient $f$ was used to simulate the combustion processes of a dual fuel diesel engine. The delay coefficient $f$ was originally calculated based on a global reaction to describe the oxidation of diesel fuel at high temperatures [18]. In the present work, the delay coefficient $f$ was calculated based on a detailed chemical kinetics and the following formulation is used to describe the reaction rate in an elementary reaction:

$$
\begin{aligned}
& \frac{c_{m}^{k}-c_{m}^{0}}{\tau}=\dot{\omega}\left(c_{m}^{k}\right) \frac{\tau_{\text {chem }}}{\tau_{\text {chem }}+f \tau_{\text {mix }}}=\frac{c_{s}^{0}[\dot{\omega}]_{s r}^{0}}{c_{s}^{0}+R_{D}^{0} \tau-f[\dot{\omega}]_{s r}^{0} \tau_{\text {mix }}} \\
& f=\frac{1-e^{-\gamma}}{1-e^{-1}}, \quad \gamma=\frac{Y_{\mathrm{CO}_{2}}+Y_{\mathrm{H}_{2} \mathrm{O}}+Y_{\mathrm{CO}}+Y_{\mathrm{CH}_{4}}+Y_{\text {cho }}}{1-Y_{\mathrm{N}_{2}}} .
\end{aligned}
$$

$Y$ is molar fraction of different species, and $\gamma$ is an indication of extent of combustion completion in a particular region, and its value varies from 0 for no combustion to 1 when fuel or oxygen is fully consumed. The delay coefficient $f$ changes from 0 to 1 depending on local combustion progress.

\subsection{Reaction Mechanism and Knock Model. A heptanes reac-} tion mechanism including 79 species and 294 reactions [14] was used to simulate diesel/methane dual fuel chemistry. The auto-ignition occurrence is strongly affected by many parameters including engine load, speed, fuel composition, and ambient temperature. When the energy released by chemical reactions is larger than the heat loss to the surroundings, the auto-ignition occurs. If this energy release is sufficiently rapid, intense pressure waves are created and knock is observed. 


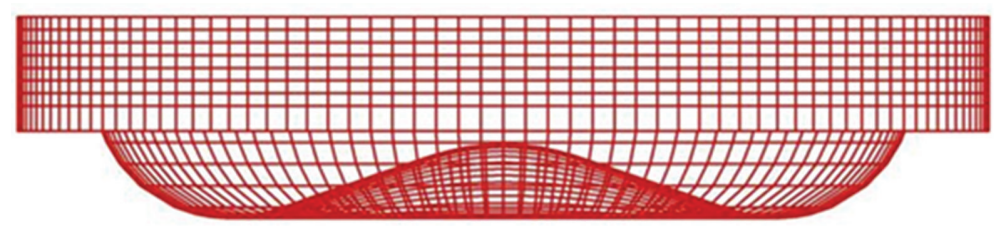

(a)

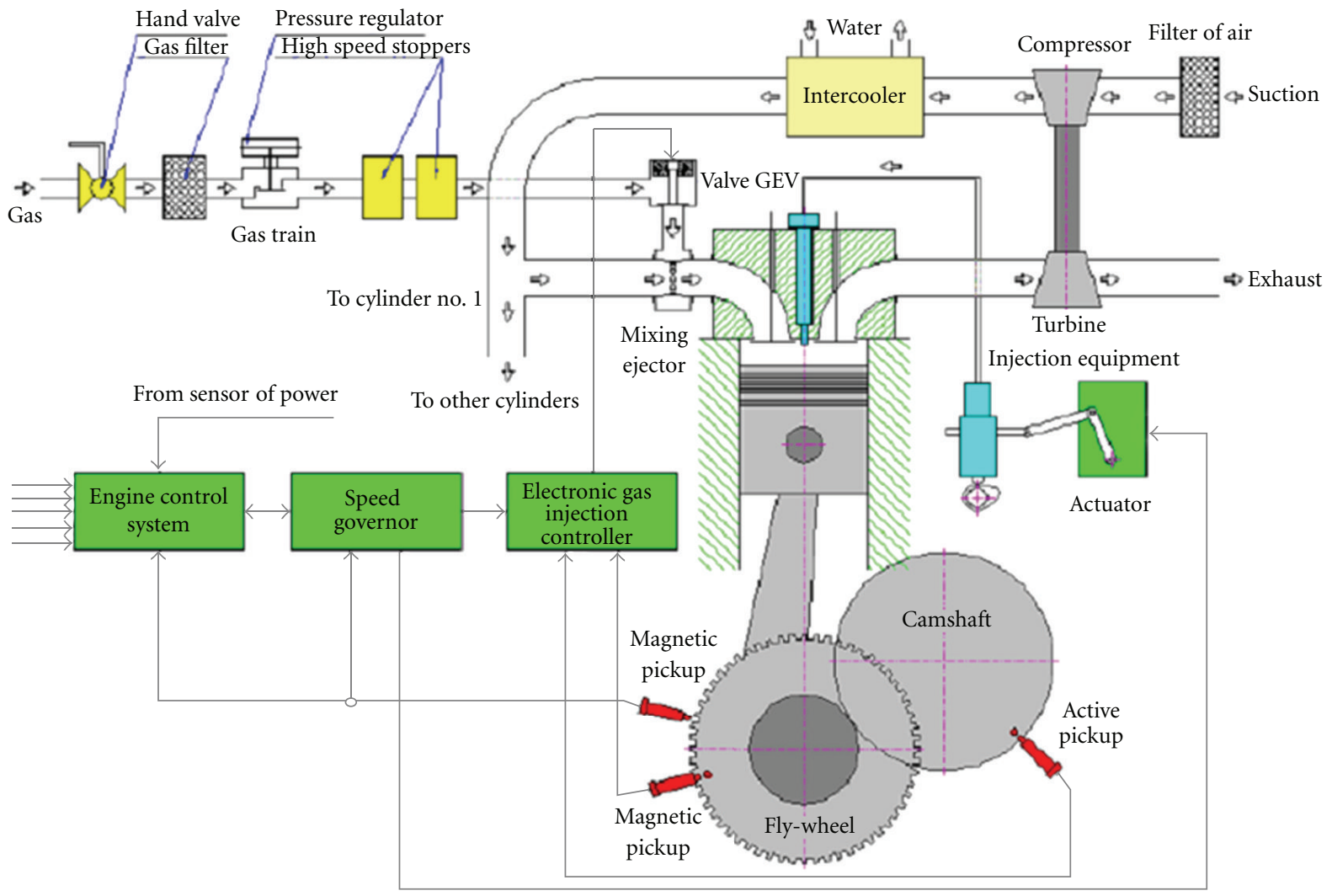

(b)

Figure 1: (a) Computational grid at TDC and (b) schematic of DF engine.

An elementary chemical reaction is generally presented by

$$
\sum_{m} a_{m r} x_{m} \Longleftrightarrow \sum_{m} b_{m r} x_{m}
$$

where $x_{m}$ is for the species $m$, while $a_{m r}$ and $b_{m r}$ are the integral stoichiometric coefficients of species on the left and right sides of the reaction $r$ and must satisfy the following mass conservation of the chemical reactions:

$$
\sum_{m}\left(a_{m r}-b_{m r}\right) W_{m}=0
$$

where $W_{m}$ is the molecular weight and the rate of reaction $r$ is given by:

$$
\dot{w}_{r}=k_{\mathrm{fr}} \prod_{m}\left(\frac{\rho_{m}}{W_{m}}\right)^{\dot{a}_{m r}}-k_{\mathrm{br}} \prod_{m}\left(\frac{\rho_{m}}{W_{m}}\right)^{\dot{b}_{m r}}
$$

where $\dot{a}_{m r}$ and $\hat{b}_{m r}$ are empirical reaction orders, which could be equal to $a_{m r}$ and $b_{m r} . \rho_{m}$ is the mass density of species $m$. $k_{\mathrm{fr}}$ and $k_{\mathrm{br}}$ are the coefficients of the forward and backward reactions in the generalized Arrhenius form.

Finally, for temperature of mixture, the same procedure can be applied:

$$
\frac{d T}{d t}=\frac{\left(\rho_{m} / W_{m}\right)}{c_{p m}(d Q / d t)}+\frac{\left(\rho_{m} / W_{m}\right)}{c_{p m}(d P / d T)}-\frac{1}{c_{p m}} \frac{\sum_{m} h_{f} W_{m}}{\rho_{m} \sum_{r} \dot{w}_{r}} .
$$

The above equations give stiff ordinary differential equations for variation of pressure, temperature, and mass fractions.

2.3. Initial Conditions, Engine Specification, and Test Instruments. Initial conditions of combustion were obtained from flow field simulation [15]. Calculations started from intake valve closure while generating mesh containing $25000 \mathrm{com}-$ putational cells at BDC (Figure 1(a)) to analyze the combustion process. 


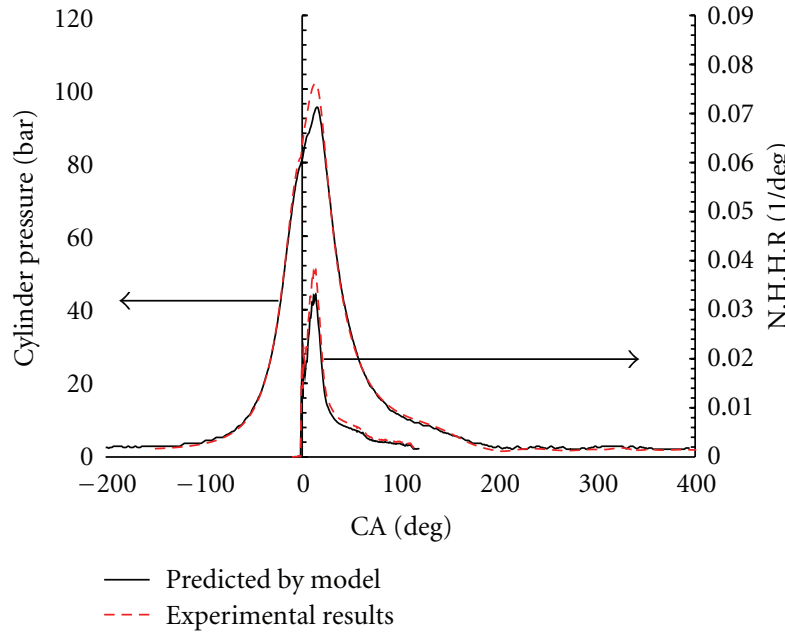

(a)

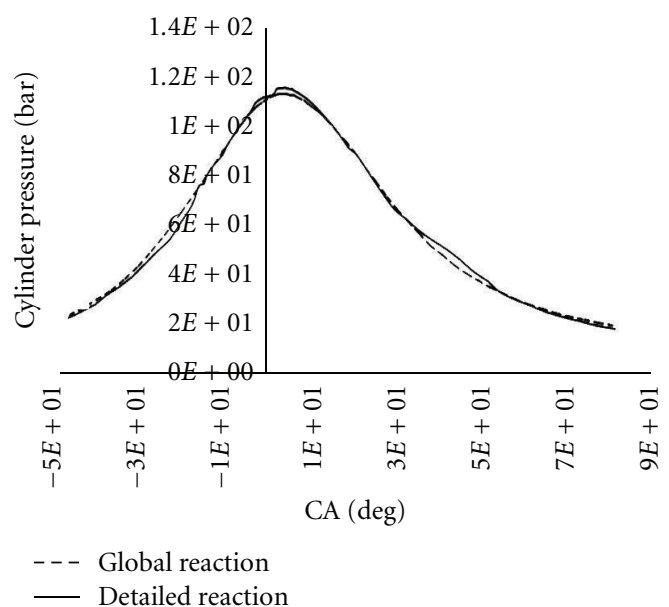

(b)

Figure 2: (a) Numerical and experimental results of cylinder pressure and normalized heat release rate and (b) calculated cylinder pressure (volume mean).

TABLE 1: Engine specification and operation conditions.

\begin{tabular}{lc}
\hline Engine & 4 strokes \\
Fuel & Natural gas-diesel oil \\
$\mathrm{B} \times \mathrm{S}$ & $150 \mathrm{~mm} \times 180 \mathrm{~mm}$ \\
$\mathrm{CR}$ & $11.5: 1$ \\
$N$ & $1500 \mathrm{RPM}$ \\
Gas injection & Starting: $10^{\circ} \mathrm{AIVO}$ \\
& Duration: $130^{\circ} \mathrm{CA}$ \\
Diesel oil pilot injection & Starting: $34^{\circ} \mathrm{BTDC}$ \\
& Duration: $24^{\circ} \mathrm{CA}$ \\
Number of nozzle's holes & 8 \\
Nozzle diameter & $0.25 \mathrm{~mm}$ \\
Fuel metering & Diesel oil: $37 \mathrm{mg} / \mathrm{cycle}$ \\
Charged air pressure & Natural gas: $317.5 \mathrm{mg} / \mathrm{cycle}$ \\
Charged air temperature & $1.11 \mathrm{bar}$ \\
Turbine inlet temperature & $45^{\circ} \mathrm{C}$ \\
Turbine outlet temperature & $585^{\circ} \mathrm{C}$ \\
Overall AFR & $491^{\circ} \mathrm{C}$ \\
\hline
\end{tabular}

TABLe 2: Natural gas composition used in DF engine.

\begin{tabular}{lcc}
\hline Species & Molecular composition & Mole fraction\% \\
\hline Methane & $\mathrm{CH}_{4}$ & 90.30 \\
Ethane & $\mathrm{C}_{2} \mathrm{H}_{6}$ & 4.28 \\
Propane & $\mathrm{C}_{3} \mathrm{H}_{8}$ & 0.63 \\
Butane & $\mathrm{C}_{4} \mathrm{H}_{10}$ & 0.08 \\
Nitrogen & $\mathrm{N}_{2}$ & 3.6 \\
\hline
\end{tabular}

The engine used in this study is a newly developed heavyduty diesel engine in dual fuel mode of operation using natural gas as main fuel and diesel oil as pilot injection. This engine has 12-cylinders, which is built in DESA Company
TABLe 3: Simulation and experimental results.

\begin{tabular}{lcc}
\hline Parameter & Simulation & Experimental \\
\hline BMEP & $13.1 \mathrm{bar}$ & $13.3 \mathrm{bar}$ \\
BSFC & $244.7 \mathrm{~g} / \mathrm{kWh}$ & $221 \mathrm{~g} / \mathrm{kWh}$ \\
Brake power $(\mathrm{kW})$ & 624.5 & 636.9 \\
Maximum cylinder pressure & $95.07 \mathrm{bar}$ & $101.92 \mathrm{bar}$ \\
Maximum pressure occurrence & $13.53 \mathrm{deg}$ ATDC & $15.3 \mathrm{deg}$ ATDC \\
Start of combustion & $-1.42 \mathrm{deg}$ ATDC & $0.74 \mathrm{deg}$ ATDC \\
$\mathrm{NO}_{x}$ at full load & $6.3 \mathrm{~g} / \mathrm{kWh}$ & $6.6 \mathrm{~g} / \mathrm{kWh}$ \\
\hline
\end{tabular}

and its schematic diagram is shown in Figure 1(b) and its specifications are presented in Table 1. The used dynamometer is counter flow type and is built at SCHENCK Company. This dynamometer inducts load to engine by using an electrical brake for simulation the various modes of operations. The dynamometer is cooled by water and can be used up to $1100 \mathrm{~kW}$ output power. The accuracy of dynamometer is determined per each 24 hours and the allowed error at constant load is 0.4 N.m and at variable load is 1.5 N.m. Fuel metering system is the kind of AVL-735 and pressure sensor which is used for measuring the in-cylinder pressure is the kind of KISTLER with the range of 0-250 bar. The emission analyzer which is used to calculate the exhaust emission such as $\mathrm{NO}_{x}$, is the model of Horiba-7170D with maximum 3\% error in measurements.

Natural gas composition used during development tests of the engine in dual fuel mode of operation is presented in Table 2. As shown in Figure 1(b), the natural gas is premixed with air through intake ports and enters into the cylinder.

\section{Results and Discussion}

Some of the main in-cylinder experimental and numerical results are presented in Table 3; Also, Figure 2(a) shows 


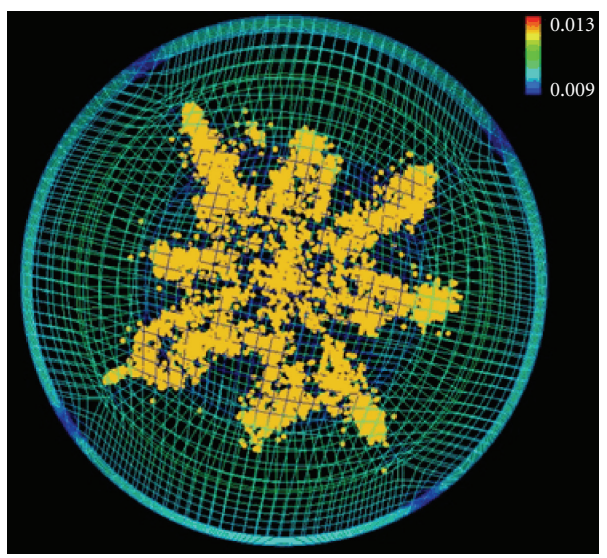

(a)

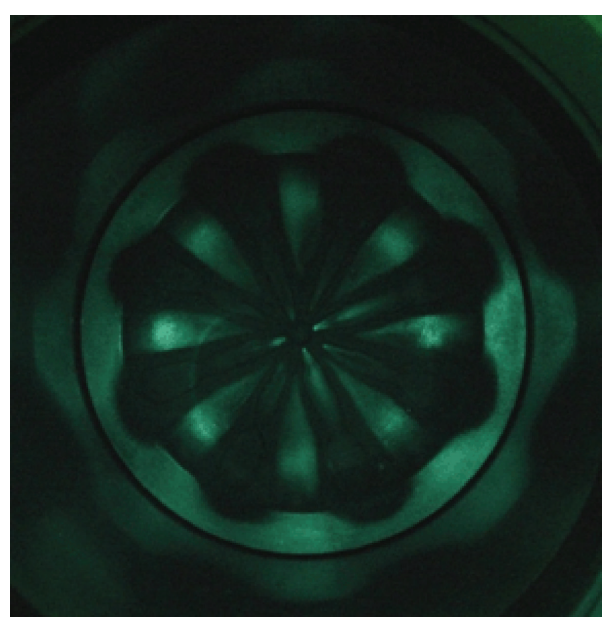

(b)

FIGURE 3: (a) Numerical simulation results and (b) flow pattern results.

numerical and experimental results for in-cylinder pressure and normalized heat release rate. There is a good agreement between numerical model and experimental results which signifies the accuracy of developed reduced chemical kinetics model which was used for combustion modeling. Comparison of temporal development of the volume means pressure when using a global reaction rate model for oxidation of methane and using superior detailed chemical kinetics model are shown in Figure 2(b). The latter approach give a more accurate features of the instantaneous pressure changes within the cylinder, while the use of a gross kinetic model only signify some important details. Therefore, the need to employ a detailed kinetics simulation rather than applying a gross kinetics simulation for preignition and combustion reactions is evident.

Injection flow patterns results from model calculation and test visualization are shown in Figures 3(a) and 3(b), respectively. The injectors, which are used, have eight holes and of $0.25 \mathrm{~mm}$ diameter. The injection pressure is set at 600 bars and the engine running at 850 RPM, which is the idle speed, without any preinjection. After engine working for about 150 hours, the engine head cylinder has been taken off for inspection. While inspecting the pattern of the fuel injected on impingement on the piston crown can be clearly seen, which shows the fuel injected by an injector unit within a cylinder.

Temperature and $\mathrm{NO}_{x}$ mass fraction variations during combustion process are shown in Figures 4(a) and 4(b) respectively. $\mathrm{NO}_{x}$ formation that increases with temperature during combustion is clearly shown in these figures. Figure 5(a) shows the methane mass fraction during combustion period. As it is shown, mass fraction of methane decreases while combustion proceeds.

The mole fraction of methane, $\mathrm{CH}_{3}$, and $\mathrm{CH}_{2} \mathrm{O}$ are presented in Figure 5(b). $\mathrm{CH}_{3}$ and $\mathrm{CH}_{2} \mathrm{O}$ are two main intermediate species that are produced during combustion and are consumed later on. The rate of production and consumption of these two species can be a very good representative of combustion rate.
3.1. Effect of Intake Temperature and Pressure on Knock Occurrence. Increasing the percentage of natural gas in dual fuel engines lead to a decrease in engine output power. To overcome the deficiency, a turbo charger with higher boost may be used which increases the intake pressure and temperature. Increasing intake temperature and pressure may enhance the occurrence of knock that should be prevented. Here, different intake temperature and pressure from the turbo charger for dual fuel engine is studied. Results show that by increasing the intake temperature and pressure, knock enhances and engine is working longer under knock conditions. Figure 6 represents the maximum pressure of cylinder for two sets of intake temperature and pressure. In Figure 6(a) the intake pressure is 2.8 bar and temperature of intake air is $380 \mathrm{~K}$ while in Figure 6(b) pressure and temperature are increased to 3.8 bar and $430 \mathrm{~K}$ respectively. As shown in these figures, increasing the intake pressure and temperature enhances knock occurrence and lead to higher maximum in-cylinder pressure that means engine works under more severe knock conditions and engine is more vulnerable to damages. These figures indicate that the increase in the intake pressure also can shorten the auto-ignition timing and increase maximum cylinder pressure. This is mainly the result of increasing both the level of cylinder pressure and the mass of the fuel-air mixture being compressed.

\subsection{Effect of Initial Swirl Ratio on Combustion Characteristics.} The effects of initial swirl ratio on, in-cylinder temperature, heat release rate, heat loss to the walls, combustion delay, and emission are shown in Figures 7 and 8. As mentioned in previous section, to increase the power of a dual fuel engine to approach the same level as the pure diesel, intake boost pressure is increased. However, the difficulty arises due to risk of knock occurrence. To overcome this situation that is to decrease the pressure and temperature by increasing the swirl of flow and as a result increasing the heat loss to the walls. In Figure 7(a), the effects of initial swirl ratio on cylinder temperature is presented. It is seen that the increased swirl 


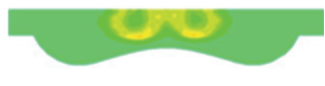

Crank $=2^{\circ}$ ATDC

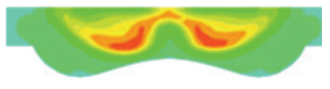

Crank $=10^{\circ}$ ATDC

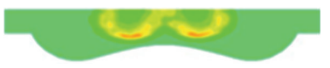

Crank $=4^{\circ}$ ATDC

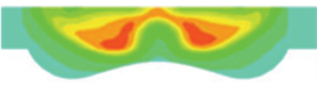

Crank $=12^{\circ}$ ATDC

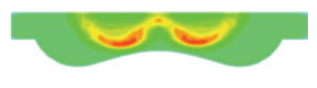

Crank $=6^{\circ}$ ATDC

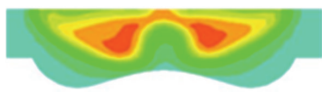

Crank $=14^{\circ}$ ATDC
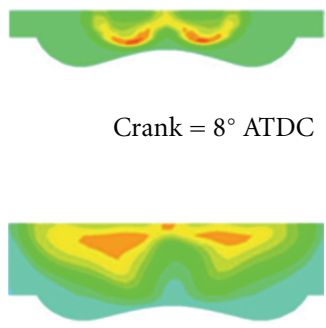

Crank $=20^{\circ}$ ATDC

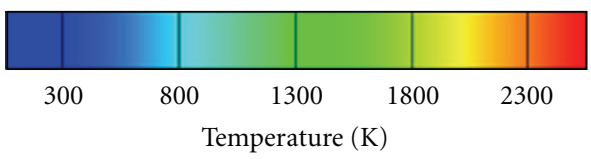

(a)

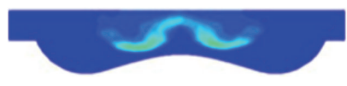

Crank $=2^{\circ}$ ATDC

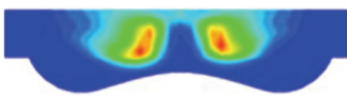

Crank $=10^{\circ}$ ATDC

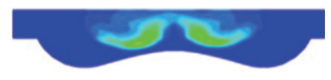

Crank $=4^{\circ}$ ATDC

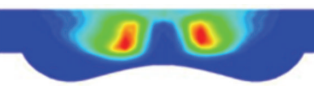

Crank $=12^{\circ}$ ATDC

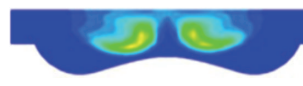

Crank $=6^{\circ}$ ATDC

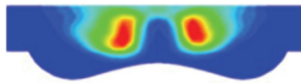

Crank $=14^{\circ}$ ATDC

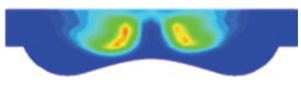

Crank $=8^{\circ}$ ATDC

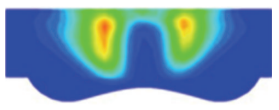

Crank $=20^{\circ}$ ATDC

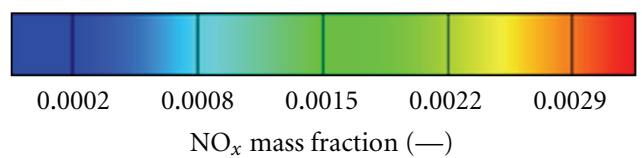

(b)

FIGURE 4: (a) Predicted in-cylinder temperature distribution and (b) predicted in-cylinder $\mathrm{NO}_{x}$ mass fraction concentration.

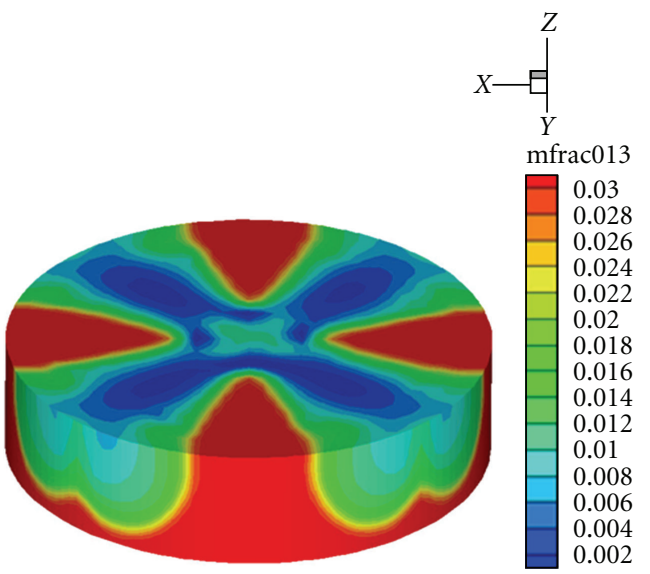

(a)

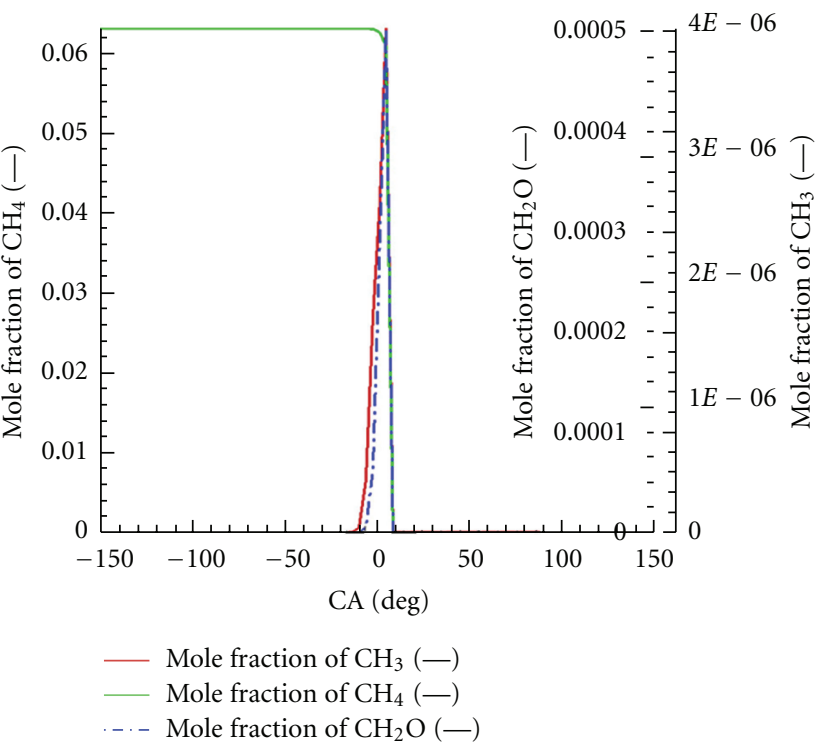

(b)

Figure 5: (a) Predicted methane mass fraction versus combustion duration and (b) mole fraction of methane, $\mathrm{CH}_{3}$, and $\mathrm{CH}_{2} \mathrm{O}$ [-]. 


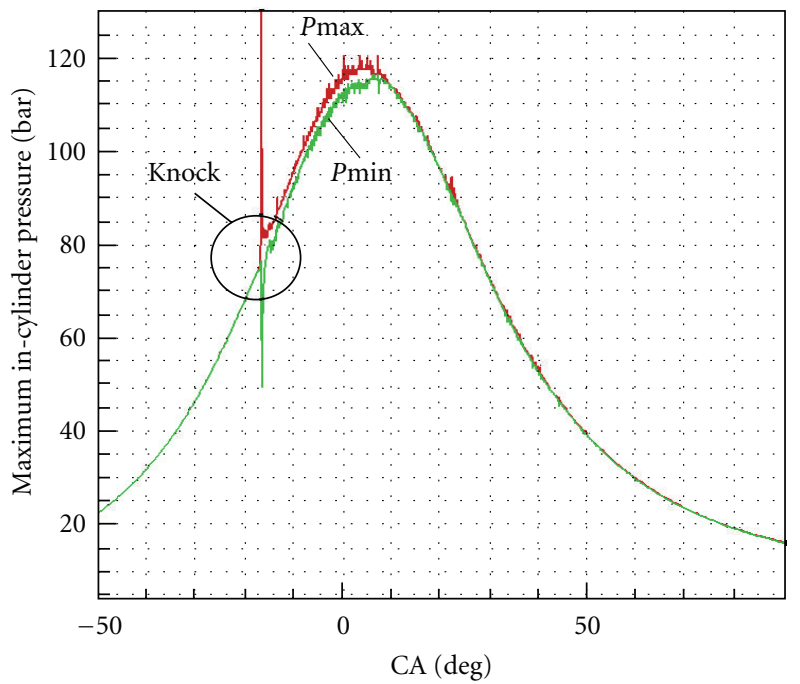

(a)

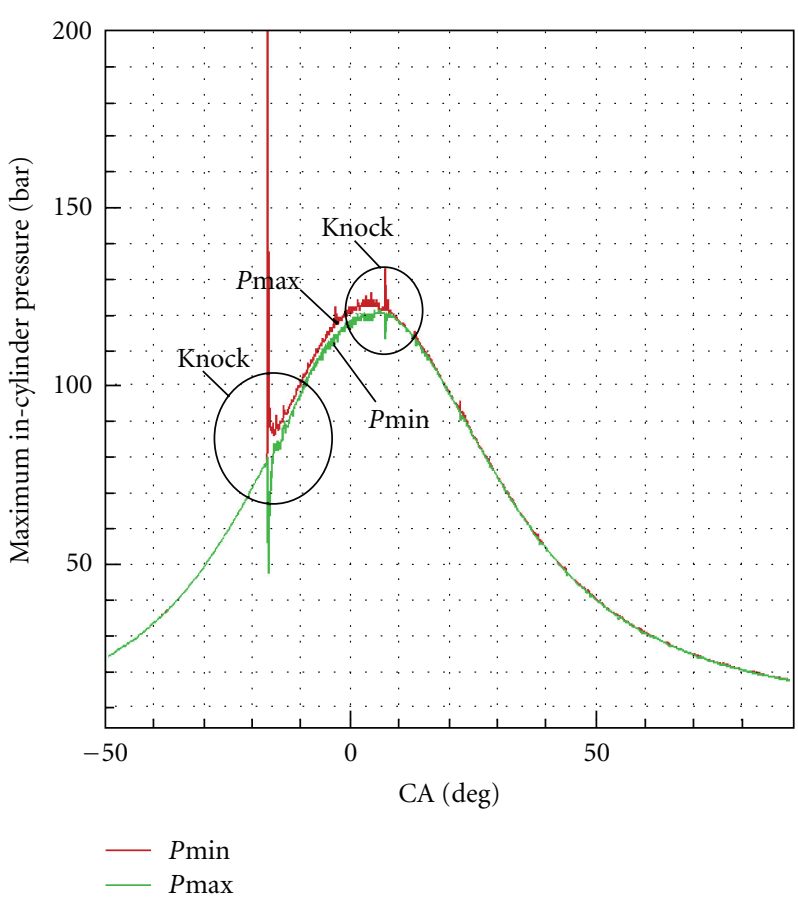

(b)

Figure 6: (a) Effects of intake temperature and pressure on knock occurrence ( $\mathrm{T}$-in $=380^{\circ} \mathrm{K}$ and P-in $=2.8$ bar) and (b) effect of intake temperature and pressure on knock occurrence $\left(\mathrm{T}-\mathrm{in}=430^{\circ} \mathrm{K}\right.$ and $\mathrm{P}-\mathrm{in}=3.8 \mathrm{bar}$ ), predicted by KIVA3V.

TABLE 4: Effect of initial swirl ratio on ignition delay.

\begin{tabular}{lc}
\hline Initial swirl ratio & Ignition delay (degree) \\
\hline 0 & 5.0 \\
2 & 6.5 \\
4 & 6.0 \\
6 & 5.0 \\
8 & 4.8 \\
\hline
\end{tabular}

tends to reduce the maximum temperature and the nonhomogeneity of the distribution of temperature and pressure within the cylinder. The effects of initial swirl ratio on $\mathrm{NO}_{x}$ emission is shown in Figure 7(b). Generally increasing the initial swirl ratio reduces the in-cylinder temperature which in terms would reduce thermal $\mathrm{NO}_{x}$. However, when the swirl ratio is increased drastically, for example, by four times, $\mathrm{NO}_{x}$ formation enhances due to incidence between oxygen and nitrogen molecules. It also can be seen from Figure 7(c) that the thermal efficiency decreases with the increase in the initial swirl ratio mainly due to the increase of heat loss and later ignition. Therefore, the value of the initial intake swirl ratio could be optimized to obtain relatively higher thermal efficiency and lower $\mathrm{NO}_{x}$ emissions while avoiding knock.

Increasing swirl ratio would lead to earlier occurrence of the maximum temperature but the net amount decreases due to excess heat loss to the walls that can be seen on earlier prereactions model shown in Figure 7(c). This figure shows that any increase in swirl ratio could lead to increase in heat loss. By increasing the heat loss, net heat release decreases. In addition, combustion initiation, which leads to heat release, is affected by swirl ratio. Initially increasing the swirl ratio would increase heat loss. This heat loss would hamper prereactions but when the swirl ratio is increased drastically, the turbulence initiated in flow causes the growth of prereactions that leads to earlier occurrence of heat release initiation point, when swirl ratio increases; the physical ignition delay overcomes the chemical ignition delay, therefore the global ignition delay decreases. These results are shown in Figure 7(d) and Table 4. It can be seen that the heat released rate becomes lower, and the time required to finish the combustion becomes longer as the initial swirl ratio is increased.

Figure 8 shows the effects of initial swirl ratio on turbulent kinetic energy and its dissipation. The minimum value of the turbulence kinetic energy increases with increasing the initial intake swirl ratio. Also, by increasing the swirl and therefore increasing the turbulence of flow, the turbulent kinetic energy peak take places earlier and in high swirl ratio two peaks are visible (Figure 8(a)). First peak is related to the turbulence and second is related to the combustion. In fact, in swirl ratio higher than four, the behavior of flow is huge turbulent and so its effect on in-cylinder parameters is more drastic. Figure 8(b) shows that in major turbulent flow, amount of energy dissipation is higher. This means that the tendency to knock is decreasing and engine works at a safer region of operation.

\section{Conclusions}

In this study, combustion of a newly designed dual fuel engine has been simulated numerically by using the chemical 


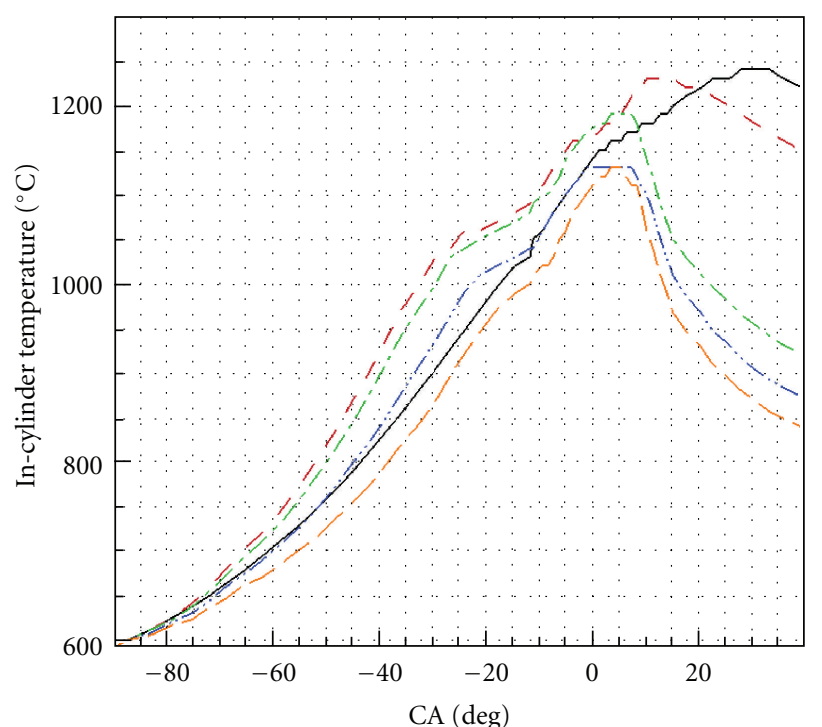

(a)

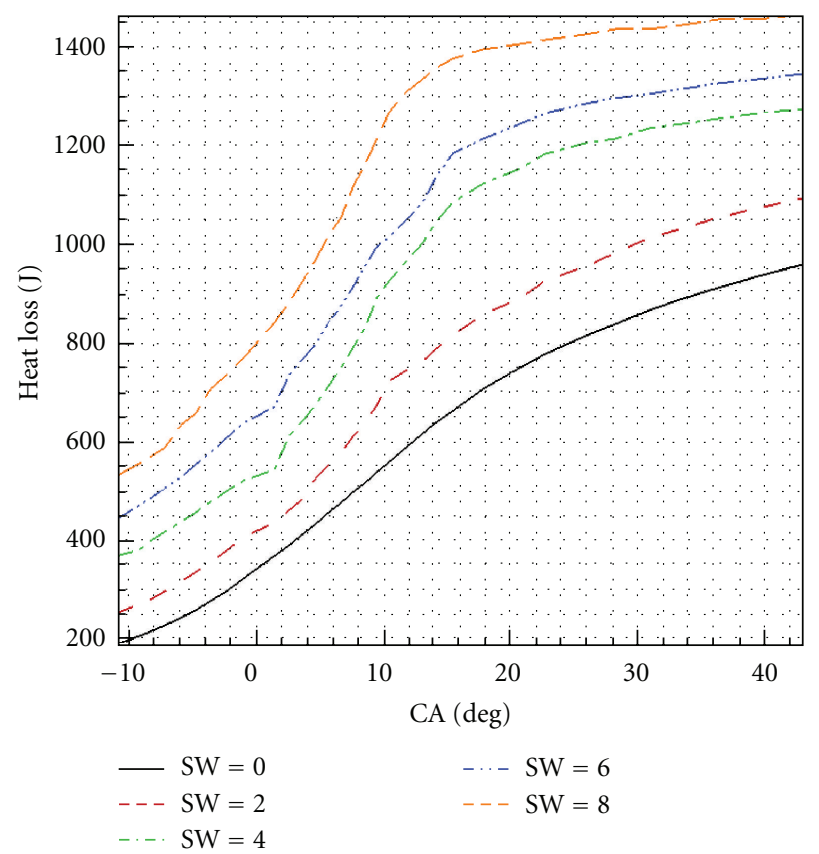

(c)

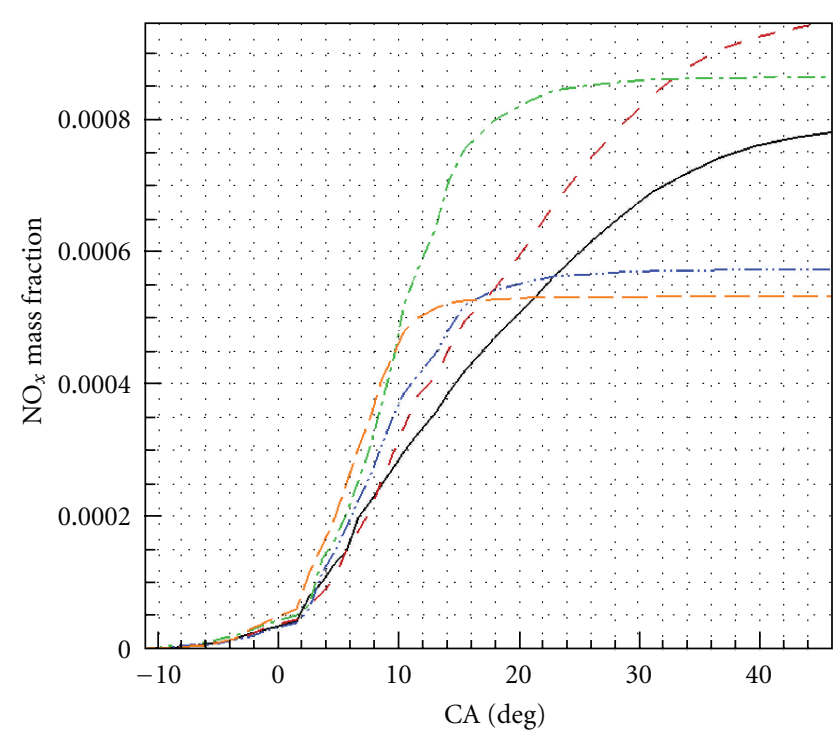

(b)

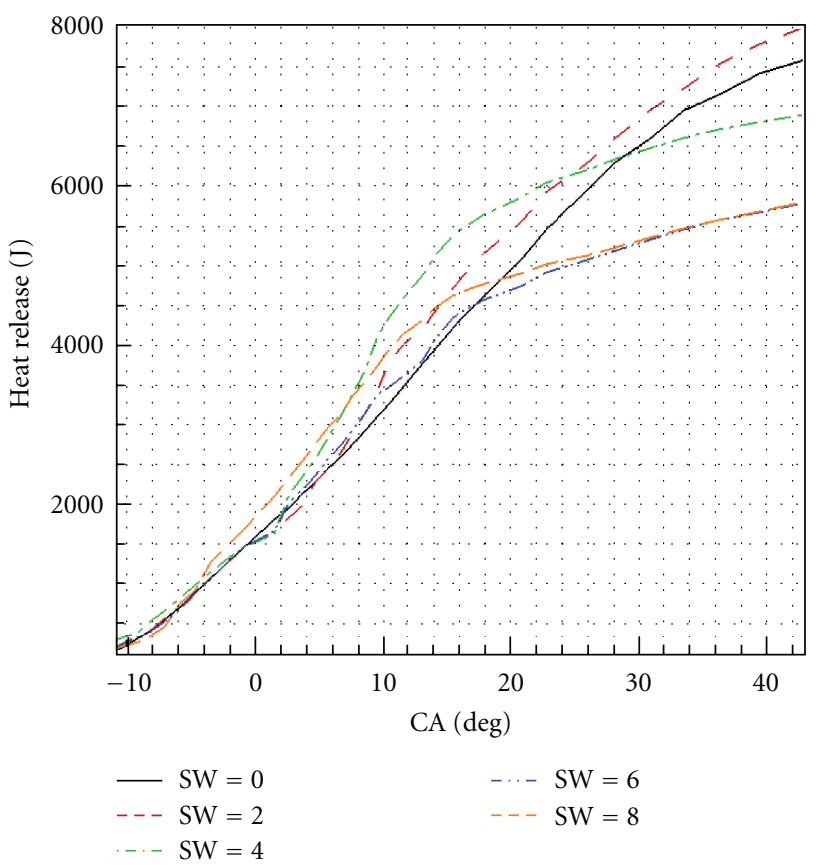

(d)

FIGURE 7: (a) Effect of initial swirl ratio on the in cylinder temperature and (b) effect of initial swirl ratio on $\mathrm{NO}_{x}$ formation. (c) effect of initial swirl ratio on the heat loss through the walls and (d) effect of initial swirl ratio on the heat release, predicted by KIVA3V.

kinetics mechanism combined with partially stirred combustion model. The results are validated with the experimental results available for in-cylinder pressure distribution, $\mathrm{NO}_{x}$ formation, and fuel injection pattern. The results are in good agreement with experimental data. The results can be summarized as follows.

(i) Detailed chemical kinetic models need to be employed to represent the development of the combustion processes and provide detailed information about the combustion characteristics of dual fuel engines, better than when global reactions are assumed.

(ii) The increase of initial intake swirl ratio in dual fuel engines can reduce $\mathrm{NO}_{x}$ emissions, the maximum and minimum cylinder pressure and temperature, and the possibility of knock, while increasing heat loss.

(iii) By increasing intake temperature and pressure, the amount of power loss in dual mode of operation is 


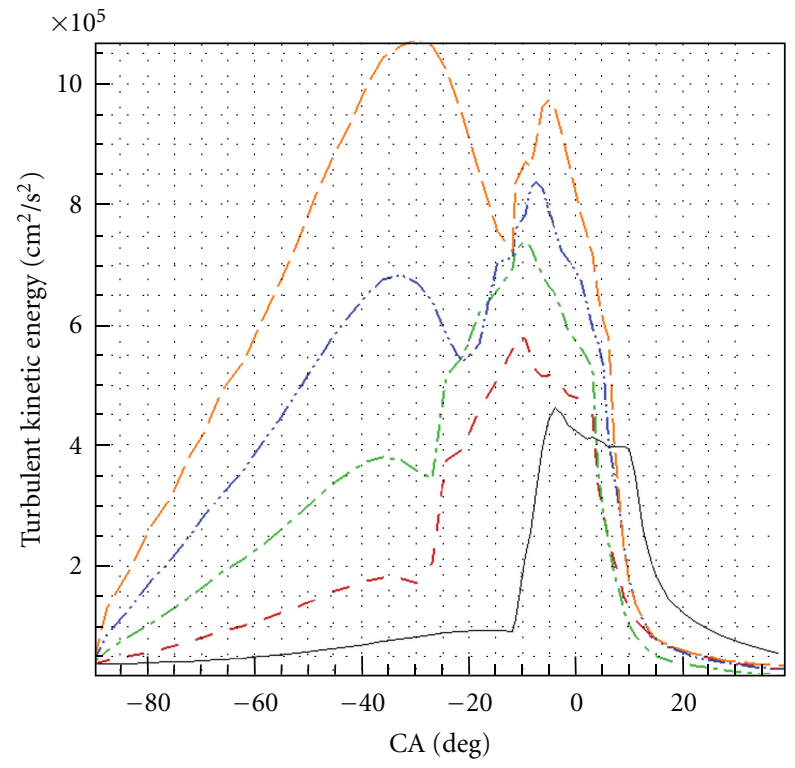

(a)

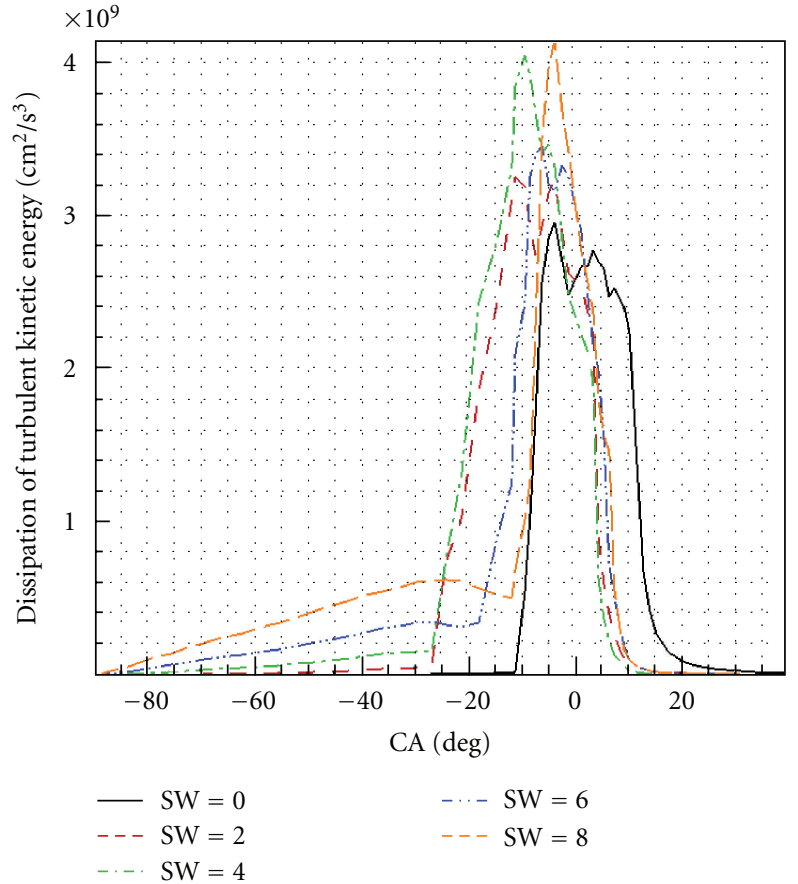

(b)

Figure 8: (a) Effect of initial swirl ratio on turbulent kinetic energy and (b) effect of initial swirl ratio on dissipation of turbulent kinetic energy, predicted by KIVA3V.

reduced; however, this increase may lead to initiation of knock and engine damage.

(iv) Simultaneous increase of intake pressure and initial swirl ratio could be the best solution; overcoming the power loss in dual fuel engine at the same time prevention of knock occurrence.

(v) Swirl ratio also influences the ignition delay by exchanging the portion of physical and chemical ignition delay. The value of initial intake swirl ratio and pressure may be optimized for any set of engine operating conditions to obtain a high thermal efficiency and low $\mathrm{NO}_{x}$ emissions while reducing the tendency to knock in dual fuel engines.

\section{Nomenclature}

B: $\quad$ Bore $(\mathrm{mm})$

$E_{a}$ : Activation energy

$E_{\mathrm{br}}$ : Backward activation temperature for a reaction, $\mathrm{k}$

$E_{\mathrm{fr}}$ : Forward activation temperature for a reaction, $\mathrm{k}$

$k$ : Turbulence kinetics energy, $\mathrm{cm}^{2} / \mathrm{s}^{2}$

$k_{\text {br }}$ : Backward reaction rate constants for $r$ th reaction

$k_{\mathrm{cr}}$ : Equilibrium constant for $r$ th reaction

$k_{\mathrm{fr}}$ : Forward reaction rate constants for $r$ th reaction
$N: \quad$ Engine speed, RPM

$P: \quad$ Absolute pressure $(\mathrm{kPa})$

$Q: \quad$ Heat transfer

$Q_{c}$ : Source due to chemical heat release

S: $\quad$ Stroke $(\mathrm{mm})$

SW: Initial swirl ratio

T: $\quad$ Temperature (k)

$P$ : $\quad$ Absolute pressure $(\mathrm{kPa})$

$\omega_{m}: \quad$ Reaction rate of species $m$

$\rho_{m}$ : Mass density of species $m$

$W m$ : Molecular weight of species $m$.

\section{Abbreviations}

ABDC: After bottom dead center

AIVO: After intake valve opening

ATDC: After top dead center

BDC: Bottom dead center

BMEP: Brake mean effective pressure

BSFC: Brake specific fuel consumption, g/kWh

CA: Crank angle, degree

CFD: Computational fluid dynamic

HRR: Heat release rate, J/deg

NHRR: Normalized heat release rate

PSR: Perfectly stirred reactor

TDC: Top dead center

THC: Total hydrocarbons.

\section{Acknowledgment}

The authors would like to thank engineering and development team at Iran Heavy Diesel Engine Mfg. Company for 
providing data and required instruments and facilitating for experimental tests.

\section{References}

[1] G. A. Karim, "A review of combustion processes in the dual fuel engine-the gas diesel engine," Progress in Energy and Combustion Science, vol. 6, no. 3, pp. 277-285, 1980.

[2] G. A. Karim, "An examination of some measures for improving the performance of gas fuelled diesel engines at light load," in Proceedings of the SAE International Fuels \& Lubricants Meeting \& Exposition, no. 912366, October 1991.

[3] Z. Liu and G. A. Karim, "An analytical examination of the pre ignition processes within homogeneous mixtures of a gaseous fuel and air in a motored engine," in Proceedings of the SAE International Fuels \& Lubricants Meeting \& Exposition, no. 942039, 1994.

[4] V. Pirouzpanah and B. O. kashani, "Prediction of major pollutants emission in direct- injection dual fuel diesel and natural gas engines," in Proceedings of the International Congress \& Exposition, no. 1999-01-0841, 1999.

[5] G. H. Abd-Alla, H. A. Soliman, O. A. Badr, and M. F. A. Rabbo, "The effects of diluents admission and intake temperature in exhaust gas recirculation on the emissions of an indirectinjection, dual fuel engine," in Proceedings of the International Fuels \& Lubricants Meeting \& Exposition, no. 2000-01-2796, 2000.

[6] D. Hountalas and R. Papagiannakis, "Development of a simulation model for direct injection dual fuel diesel-natural gas engines," in Proceedings of the SAE 2000 World Congress, no. 2000-01-0286, 2000.

[7] R. G. Papagiannakis, D. T. Hountalas, and C. D. Rakopoulos, "Theoretical study of the effects of pilot fuel quantity and its injection timing on the performance and emissions of a dual fuel diesel engine," Energy Conversion and Management, vol. 48, no. 11, pp. 2951-2961, 2007.

[8] P. Mtui, Pilot ignited natural gas combustion diesel engines, Ph.D. thesis, University of British Columbia, Vancouver, Canada, 1996.

[9] J. Kusaka, Y. Daisho, T. Shimonagata, R. Kihara, and T. Saito, "Combustion and exhaust characteristics of a diesel engine dual-fuelled with natural gas," in Proceedings of the 7th International Conference and Exhibition on Natural Gas Vehicles (IANGV'00), pp. 23-31, Yokohama, Japan, October 2000.

[10] S. Song and P. G. Hill, "Dual-fueling of a pre-chamber Diesel engine with natural gas," Journal of Engineering for Gas Turbines and Power, vol. 107, no. 4, pp. 914-921, 1985.

[11] S. C. Li and F. A. Williams, "A reduced reaction mechanism for predicting knock in dual fuel engines," in Proceedings of the SAE, no. 2000-01-0957, 2000.

[12] J. Kusaka, K. Tsazuki, and Y. Daisho, "A numerical study on combustion and exhaust gas emissions characteristics of a dual-fuel natural gas engine using a multi-dimensional model combined with detailed kinetics," in Proceedings of the Spring Fuels \& Lubricants Meeting \& Exhibition, no. 2002-01-1750, 2002.

[13] Y. Zhang, S. C. Kong, and R. D. Reitz, "Modeling and simulation of a dual-fuel (Diesel/Natural Gas) engine with multidimensional CFD," in Proceedings of the SAE 2003 World Congress \& Exhibition, no. 2003-01-0755, 2003.

[14] C. Liu, An experimental and analytical investigation into the combustion characteristics of HCCI and dual fuel engines with pilot injection, Ph.D. thesis, University of Calgary, Calgary, Canada, 2006.

[15] A. Gharehghani, M. Mirsalim, A. Jazayeri, and M. Ghanbari, "Numerical simulation of a new dual fuel (Diesel-gas) D87 engine with multi-dimensional CFD model," CIMAC Paper number 233, 2010.

[16] T. Rente, V. I. Golovichev, and I. Denbratt, "Effect of injection parameters on auto-ignition and soot formation in Diesel sprays," in Proceedings of the SAE International Fall Fuels \& Lubricants Meeting \& Exhibition, no. 2001-01-3687, 2001.

[17] A. A. Amsden, "KIVA-3V: a block-structured KIVA program for engines with vertical or canted valves," Tech. Rep. number LA-13313-MS, Los Alamos National Labs, Los Alamos NM, USA, 1997.

[18] A. Gharehghani, CFD modeling of "dual fuel engine" combustion with KIVA-3V, M.S. thesis, Amirkabir University of Technology, Tehran, Iran, 2010. 

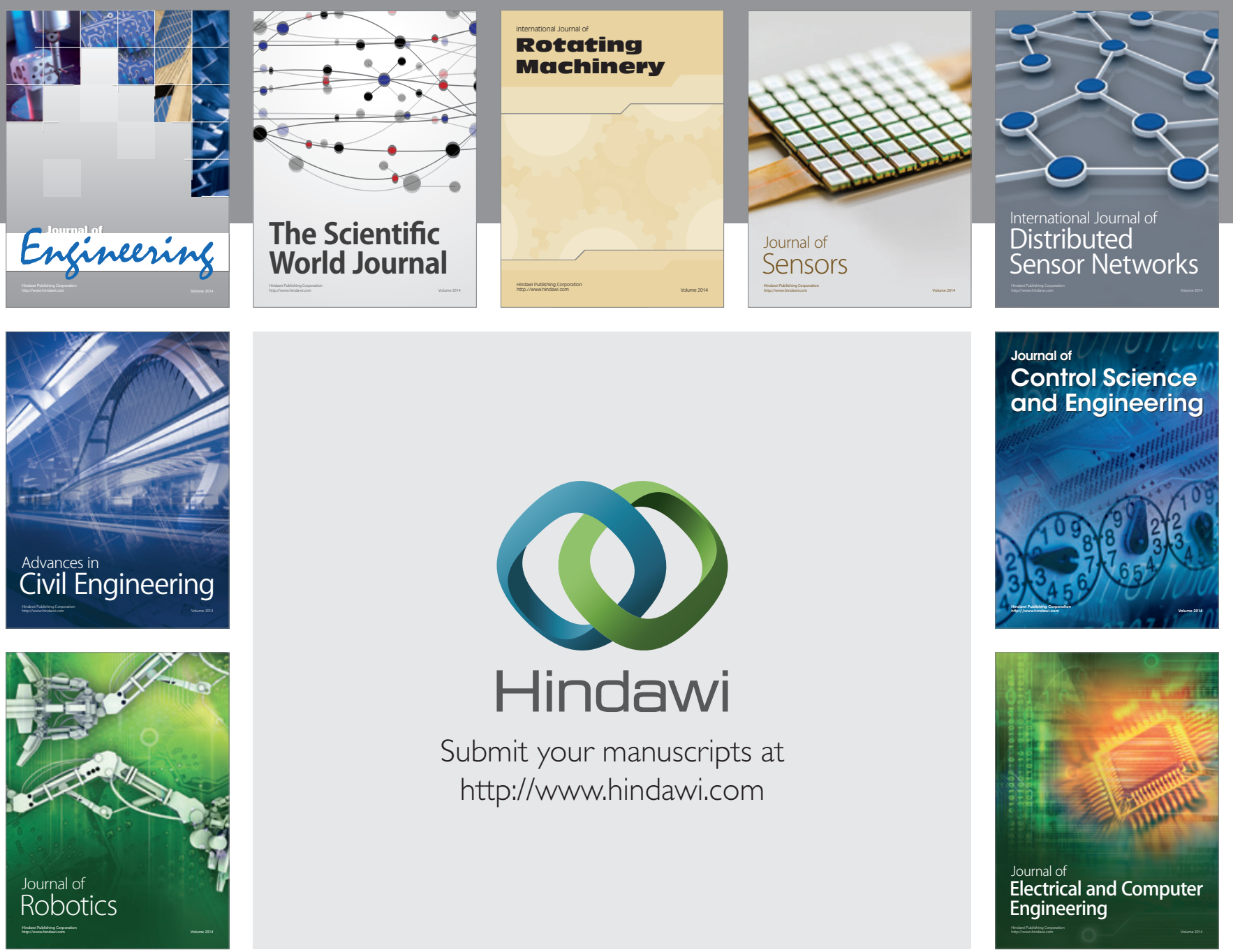

Submit your manuscripts at

http://www.hindawi.com
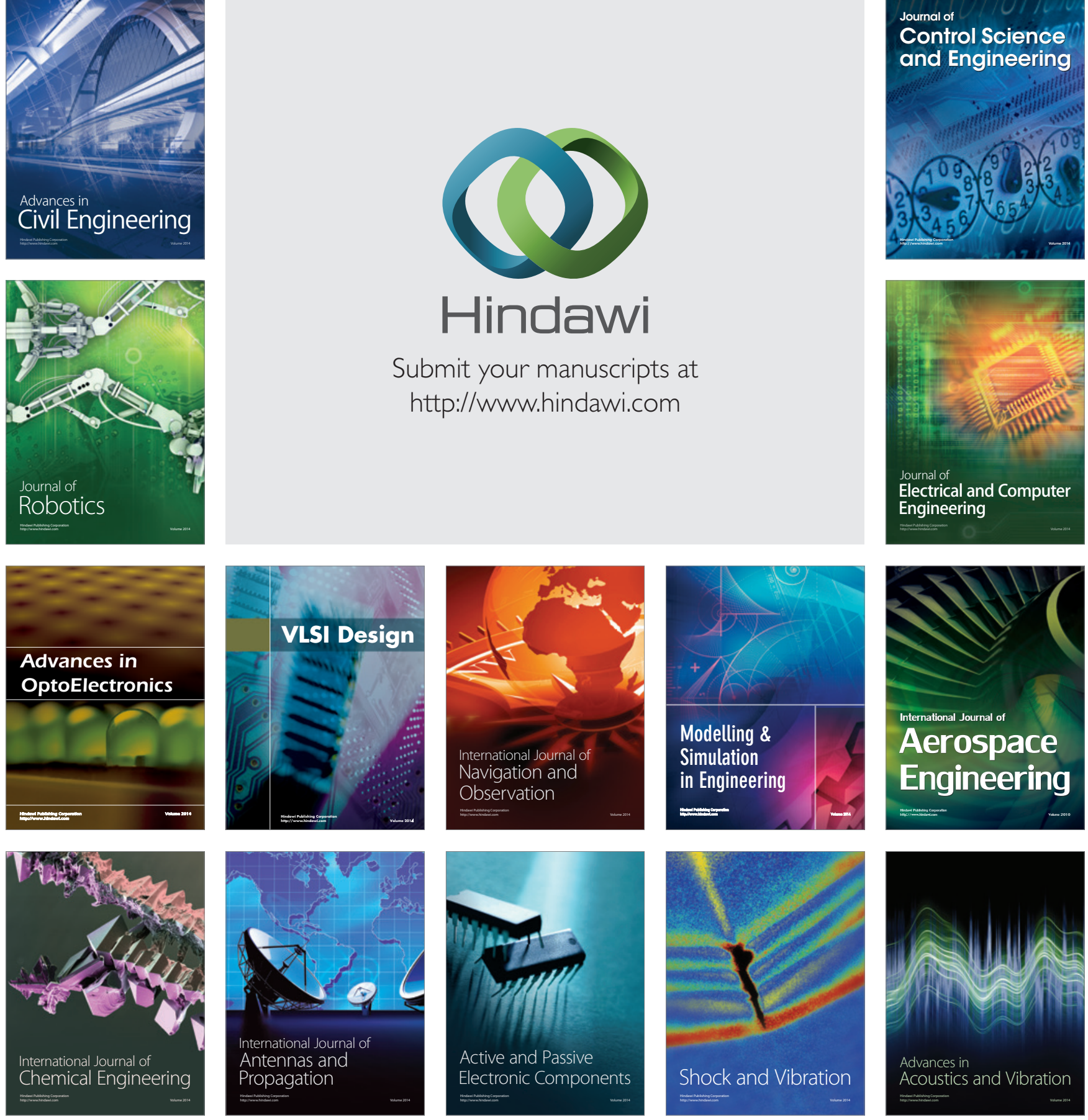